\title{
Pengaruh Sense of humor dan Religiusitas Terhadap Kebahagiaan pada Lansia
}

\author{
Ananda Rachma Aulia \& Yufi Adriani \\ Fakultas Psikologi UIN Syarif Hidayatullah Jakarta \\ adindarchma8@gmail.com, yufi.adriani@uinjkt.ac.id
}

\begin{abstract}
Happiness is what everyone wants. With happiness, individuals can feel various positive effects in influencing every aspect of life. This study aims to prove the effect of sense of humor, religiosity and demographic factors on elderly's happiness. The subject in this study were 211 elderly aged 60 years or above in DKI Jakarta. The sampling method used non-probability sampling. The instrument used were adapted and modified The Happiness Scale Interval Study (HSIS) (Kalmijn et al., 2011), Multidimensional Sense of humor Scale (MSHS) (Thorson \& Powell, 1993), and The Centrality of Religiosity Scale (CRS)(Huber \& Huber, 2012). Test the validity of measuring instruments using the Confirmatory Factor Analysis (CFA) technique and hypotesis was tested using multiple regression analysis. This results showed that there was a significant effect of sense of humor, religiosity, and demographic factors on elderly's happiness with contribution of $36.3 \%$, while the remaining $63.4 \%$ were variables outside of this study.
\end{abstract}

Keywords: Happiness, Sense of humor, Religiosity

\begin{abstract}
Abstrak
Kebahagiaan merupakan hal yang diinginkan oleh semua orang. Dengan adanya kebahagiaan, individu dapat merasakan berbagai efek positifnya dalam mempengaruhi setiap aspek kehidupan. Penelitian ini bertujuan untuk membuktikan pengaruh sense of humor, religiusitas, dan faktor demografi terhadap kebahagiaan pada lansia. Subjek dari penelitian ini adalah 211 lansia berusia 60 tahun ke atas yang tinggal di DKI Jakarta. Metode pengambilan sampel yang diperoleh menggunakan non-probability sampling. Instrumen yang digunakan merupakan adaptasi serta modifikasi dari The Happiness Scale Interval Study (HSIS)(Kalmijn et al., 2011)), Multidimensional Sense of humor Scale (MSHS) (Thorson \& Powell, 1993) dan The Centrality of Religiosity Scale (CRS) (Huber \& Huber, 2012) Uji validitas instrumen dilakukan dengan menggunakan Confirmatory Factor Analysis (CFA), sedangkan uji hipotesis dilakukan dengan analisis regresi berganda. Hasil penelitian menunjukkan bahwa terdapat adanya pengaruh yang signifikan dari sense of humor, religiusitas serta faktor demografi terhadap kebahagiaan lansia sebesar $36.6 \%$, sedangkan $63.4 \%$ sisanya dipengaruhi oleh variabel di luar penelitian ini.
\end{abstract}

Kata kunci: Kebahagiaan, Sense of humor, Religiusitas 


\section{Pendahuluan}

Kebahagiaan merupakan suatu keadaan emosi positif yang secara subjektif didefinisikan oleh setiap orang. Istilah subjective well being seringkali digunakan sebagai sinonim untuk kebahagiaan dalam berbagai literatur psikologi (Snyder et al., 2015) Sedangkan Seligman (2002) menyatakan bahwa kebahagiaan itu sendiri ialah suatu kondisi dan kemampuan seseorang untuk merasakan emosi positif di masa lalu, masa depan, dan masa kini. Dengan adanya kebahagiaan seseorang akan lebih kreatif, produktif serta memungkinkan untuk memiliki umur yang lebih panjang (Carr, 2004)

Kebahagiaan adalah aspek penting yang memiliki pengaruh besar dalam kehidupan, salah satunya individu yang bahagia memiliki interaksi sosial yang lebih memuaskan, sistem kekebalan tubuh yang lebih kuat, lebih efektif dalam mengatasi stres, serta hidup lebih lama. (Lyubomirsky \& Kurtz, 2013) Hal ini pun sejalan dengan Kaliterna-Lipovčan \& Prizmić-Larsen (2016) bahwa individu yang bahagia yang lebih puas dengan kesejahteraan hidupnya, status kesehatan yang lebih baik, kepercayaan yang lebih tinggi, dan lebih terlibat aktif dalam komunitas dibandingkan individu yang tidak bahagia. Ketidakbahagiaan individu dapat diartikan sebagai suatu perasaan yang diliputi oleh rasa takut, khawatir, cemas, putus asa, tertekan, penuh amarah, hampa, merasa tidak aman dan berharga, serta tidak puas dengan kehidupan(Haybron, 2005)

Konsep kebahagiaan memang seringkali diartikan sebagai suatu keadaan emosi positif yang didefinisikan secara subjektif oleh setiap individu. Bagi seseorang mungkin kebahagiaan berarti kekayaan, kekuasaan, dan kesejahteraan selama hidup, namun dalam konsep Islam walaupun hal tersebut adalah salah satu faktor menuju kebahagiaan, namun sebenarnya itu bukanlah tujuan dalam Islam (Abde \& Salih, 2015). Konsep kebahagiaan Islam merupakan rasa yang bersemayam di hati seseorang ditandai dengan adanya kedamaian pikiran, ketenangan, dan perasaan sejahtera. Kebahagiaan tersebut pun merupakan hasil dari adanya perilaku yang benar, baik lahir maupun batin, dan diilhami oleh iman yang kuat. Sebagaimana dalam Al - Qur'an kebahagiaan diistilahkan dengan kata sa'adah yang selalu dikaitkan dengan dua syarat yaitu kebahagiaan di akhirat dan kebahagiaan hidup di dunia (Abde \& Salih, 2015).

Pada saat ini Indonesia mulai memasuki periode aging population yang ditandai dengan peningkatan usia harapan hidup yang diikuti dengan peningkatan jumlah lansia. Peningkatan jumlah penduduk lansia di Indonesia meningkat dari 18 juta jiwa $(7,56 \%)$ pada tahun 2010, hingga pada tahun 2019 sebesar 25,9 juta jiwa $(9,7 \%)$ dan diperkirakan akan terus meningkat pada tahun 2035 menjadi 48,2 juta jiwa (15,77\%) (Rokom, 2019) Berdasarkan data Badan Pusat Statistik, semakin bertambahnya usia cenderung terjadi penurunan dalam indeks kebahagiaan penduduk di Indonesia. Hal ini dilihat dari Indeks Kebahagiaan Indonesia tahun 2017 berdasarkan hasil Survei Pengukuran Tingkat Kebahagiaan (SPTK) sebesar 70,69 pada skala 0 -100. Pada kelompok usia 65 tahun ke atas berada di posisi terendah dibandingkan dengan kelompok umur lainnya. Hasil indeks kebahagiaan pada usia produktif (25 - 40) tahun menunjukan hasil 71, 13 dan pada kelompok umur lansia berada di posisi terendah dengan hasil 69, 18. Hal ini tentunya perlu menjadi perhatian karena kebahagiaan para lansia berada di posisi terendah (Berita Resmi Statistik, 2017) 
Dalam tahun 2050 jumlah penduduk lansia di Indonesia diperkirakan akan mencapai 100 juta jiwa. Maka dari itu Indonesia akan dihadapkan pada tantangan yang cukup besar dalam menghadapi fenomena ini. Salah satunya ialah bagaimana menjaga kualitas hidup lansia agar dapat menikmati masa tuanya dengan baik. Besarnya jumlah penduduk lansia di Indonesia yang semakin meningkat akan berdampak positif apabila penduduk lansia dalam keadaan sehat dan produktif, namun hal ini juga dapat berdampak negatif jika lansia memiliki masalah penurunan kesehatan yang berakibat pada peningkatan biaya layanan kesehatan, penurunan pendapatan, peningkatan disabilitas serta tidak adanya dukungan sosial dan lingkungan yang tidak ramah terhadap kondisi penduduk lansia (Ekasari et al., 2019) Maka dengan adanya informasi tersebut terkait akan terjadinya peningkatan penduduk lansia, maka dari itu peneliti ingin mengkaji kebahagiaan pada lansia.

Meskipun masa ini adalah masa senja dari fase kehidupan, tidak berarti mereka melalui masa ini secara pasif. Dengan menjalani kehidupan secara aktif, mereka akan lebih sehat dan bahagia (Santrock, 2012). Studi yang dilakukan Amerika Serikat pada lansia yang berjumlah 2.282 di usia 65 tahun ke atas menyatakan bahwa emosi positif mempengaruhi hidup, mati, dan cacat pada seseorang, serta melindungi dari kerusakan akibat penuaan. Selain itu orang yang bahagia juga memiliki kebiasaan yang lebih sehat, tekanan darah rendah, dan sistem kekebalan tubuh yang lebih baik dibandingkan dengan orang yang kurang bahagia (Seligman, 2002)

Seligman (2002) menjelaskan beberapa faktor yang mempengaruhi kebahagiaan pada individu, diantaranya seperti uang, emosi negatif, pernikahan, kehidupan sosial, kesehatan, agama, dan juga jenis kelamin. Berdasarkan hasil penelitian lainnya menunjukkan bahwa sense of humor juga merupakan salah satu faktor yang dapat mempengaruhi kebahagiaan. Sebagaimana hasil studi pada 208 warga lansia di Indonesia berusia 60 - 70 tahun menunjukkan hasil bahwa sense o f humor secara signifikan dapat meningkatkan kebahagiaan, khususnya pada lansia di desa (Latipun et al., 2019). Penelitian lainnya pun menyatakan hal yang serupa, seperti hasil studi Puspita \& Putri (2015) pada lansia berusia 60 - 85 tahun dalam mengukur pengaruh sense of humor terhadap kebahagiaan menunjukkan adanya korelasi diantara variabel tersebut. Hal ini pun sejalan dengan Monahan (2015) menyatakan humor terbukti menjadi intervensi yang bermanfaat dalam mengurangi stres, dapat memberikan harapan, kegembiraan, dan rasa optimis pada lansia. Selain itu Tse et al. (2010) menyatakan terapi humor dapat mengurangi rasa sakit, kesepian dan meningkatkan kebahagiaan dan kepuasaan hidup pada lansia.

Hal lainnya yang dapat meningkatkan kebahagiaan pada lansia adalah religiusitas. Dengan adanya penurunan fungsi organ ataupun mental pada usia lansia, menjadikan mereka lebih berusaha untuk mendekatkan dirinya kepada Tuhan. Lansia pun dapat memaknai kehidupan pasca produktif dan menggunakannya sebagai aktivitas kesehariannya. Sebagaimana studi Bengtson, Silverstein, Putney, \& Harris (2015) menunjukkan bahwa semakin bertambahnya usia akan berkorelasi positif dengan intensitas religiusitas. Dalam survei yang dilakukan oleh Gallup pada individu yang berada di usia 65 tahun ke atas sebanyak $76 \%$ menyatakan bahwa agama merupakan hal yang sangat penting di kehidupan mereka dan $16 \%$ berpendapat cukup penting (Hoyer \& Roodin, 2003) Beberapa penelitian juga menyatakan bahwa religiusitas berkorelasi positif dengan kebahagiaan. Salah satunya penelitian Abdel-Khalek (2006) menyatakan bahwa religiusitas dan kesehatan mental

http://journal.uinjkt.ac.id/index.php/tazkiya

This is an open access article under CC-BY-SA license 
berkorelasi positif dengan kebahagiaan. Peran agama juga membantu individu agar bisa mendapatkan makna, tujuan, dan kerangka kerja yang koheren untuk kehidupan di fase lansia (Hoyer \& Roodin, 2003)

Kebahagiaan individu pun dapat dipengaruhi oleh faktor demografi, khususnya pada lansia. Sebagaimana variabel yang digunakan dalam penelitian ini ialah jenis kelamin dan status tinggal bersama. Chen \& Short (2008) menyatakan bahwa pengaturan kondisi hidup merupakan hal yang penting bagi kebahagiaan lansia. Sebagaimana menurut Kehn (1995) living arragements ialah lansia yang hidup sendiri, hidup dengan pasangan atau hidup bersama anak - anaknya ataupun bersama kerabatnya akan mempengaruhi tingkat kebahagian pada lansia. Dalam penelitiannya pun menyatakan bahwa lansia yang hidup bersama pasangannya lebih bahagia dibandingkan dengan lansia yang hidup sendiri, dan lansia yang hidup sendiri lebih bahagia dibandingkan dengan yang tinggal bersama anak mereka.

Berdasarkan penjelasan berbagai fenomena dan keterbatasan penelitian terkait lansia, maka tema ini tentunya penting untuk diteliti. Dalam penelitian ini, peneliti ingin melihat pengaruh sense of humor, religiusitas dan faktor demografi terhadap kebahagiaan pada lansia.

\section{Metode}

Populasi dalam penelitian ini adalah lansia berusia 60 tahun ke atas yang tinggal di DKI Jakarta, mampu beraktivitas sehari - hari, dan bersedia menjadi responden. Adapun teknik pengambilan sampel adalah teknik non-probability sampling dengan metode penyebaran kuesioner secara online dalam bentuk google form melalui media sosial. Jumlah sampel dalam penelitian ini sebanyak 211 lansia dengan rentang usia 60 - 70 tahun sebanyak 163 orang dan 48 orang berada di usia 70 tahun ke atas. Berikut ini merupakan karakteristik responden penelitian secara keseluruhan.

Tabel 1. Gambaran Responden

\begin{tabular}{lcc}
\hline \multicolumn{1}{c}{ Karakteristik Responden } & Jumlah & N (\%) \\
\hline Jenis Kelamin & & \\
Laki - laki & 88 & $41.7 \%$ \\
Perempuan & 123 & $58.3 \%$ \\
Usia & & \\
$60-70$ tahun & 163 & $77.3 \%$ \\
$>70$ tahun & 48 & $22.7 \%$ \\
Status Tinggal Bersama & & \\
Sendiri & 16 & $7.6 \%$ \\
Hanya Pasangan & 30 & $14.2 \%$ \\
Keluarga Inti & 93 & $44.1 \%$ \\
Tiga Generasi & 70 & $33.2 \%$ \\
Lainnya & 2 & $0.9 \%$ \\
\hline
\end{tabular}

Instrumen penelitian untuk mengukur kebahagiaan yang dijadikan acuan oleh peneliti merupakan hasil adaptasi dan modifikasi dari The Happiness Scale Interval Study (HSIS) oleh 
Kalmijn, Arends, \& Veenhoven (Kalmijn et al., 2011). Instrumen ini digunakan peneliti untuk mengukur dua dimensi yaitu afektif dan kognitif dengan 10 pernyataan item menggunakan skala Likert. Sementara untuk variabel sense of humor menggunakan Multidimensional Sense of humor Scale (MSHS) oleh Thorson \& Powell (1993) dengan jumlah item sebanyak 18 pernyataan yang telah dimodifikasi untuk mengukur empat dimensi yaitu humor production, coping with humor, social uses of humor, dan social uses of humor. Kemudian untuk variabel religiusitas, peneliti mengadaptasi dan melakukan modifikasi alat ukur The Centrality of Religiosity Scale (CRS) oleh Huber \& Huber (2012) dengan 20 item untuk mengukur lima dimensi yaitu intelektual, ideologi, ibadah kelompok, ibadah individual, dan pengalaman religius.

Analisis yang digunakan pada uji validitas setiap alat ukur meggunakan Confirmatory Factor Analysis (CFA) untuk melihat model fit unidimensional dan item yang valid. Kemudian dalam menguji hipotesisi penelitian menggunakan analisis regresi berganda (multiple regression analysisi) untuk melihat pengaruh variabel bebas atau independent variable terhadap variabel terikat atau dependent variable menggunakan estimasi true score.

\section{Hasil dan Diskusi}

Tabel 2. Model Summary Analisis Regresi

\begin{tabular}{ccccc}
\hline Model & $\mathbf{R}$ & $\begin{array}{c}\mathbf{R} \\
\text { Square }\end{array}$ & $\begin{array}{c}\text { Adjusted } \\
\text { R Square }\end{array}$ & Std. Error of the estimate \\
\hline 1 & .605 & .366 & .330 & 7.74253 \\
\hline
\end{tabular}

a. Predictors: (Constant), status tinggal, inetelektual, coping with humor, humor production, jenis kelamin, pengalaman religius, attitude toward humor, ibadah kelompok, ideologi, social uses of humor, ibadah individual

Berdasarkan tabel 2 dapat diketahui bahwa nilai R Square dalam penelitian ini sebesar 0.366 atau $36.6 \%$. Hal ini artinya bahwa proporsi pengaruh sense of humor (humor production, coping with humor, social uses of humor, attitude toward humor), religiusitas (intelektual, ideologi, ibadah kelompok, ibadah individual, dan pengalaman religius) dan faktor demografi (jenis kelamin dan status tinggal bersama) terhadap kebahagiaan lansia sebesar $36.6 \%$, sedangkan $63.4 \%$ sisanya dipengaruhi oleh variabel lain di luar dari penelitian ini.

Tabel 3. Anova

\begin{tabular}{lccccc}
\hline & $\begin{array}{c}\text { Sum of } \\
\text { Squares }\end{array}$ & Df & Mean Square & F & Sig. \\
\cline { 1 - 5 } Regression & 6873.397 & 11 & 624.854 & 10.423 & $.000^{\mathrm{a}}$ \\
Residual & 11929.417 & 199 & 59.947 & & \\
Total & 18802.814 & 210 & & & \\
\hline
\end{tabular}

a. Predictors: (Constant), status tinggal, inetelektual, coping with humor, humor production, jenis kelamin, pengalaman religius, attitude toward humor, ibadah kelompok, ideologi, social uses of humor, ibadah individual

b. Dependent Variable: kebahagiaan

http://journal.uinjkt.ac.id/index.php/tazkiya

This is an open access article under CC-BY-SA license 
Pada tabel 3 dapat diketahui nilai signifikansi dari keseluruhan independent variable terhadap dependent variable. Berdasarkan uji $\mathrm{F}$ pada tabel di atas dapat dilihat bahwa hasil uji $\mathrm{F}$ sebesar 10.423 dengan sig 0.000 ( $\mathrm{sig}<0.05$ ), maka hipotesis nihil yang menyatakan tidak ada pengaruh yang signifikan antara sense of humor dan religiusitas terhadap kebahagiaan ditolak. Artinya, ada pengaruh yang signifikan secara bersama - sama dari variabel sense of humor (humor production, coping with humor, social uses of humor, attitude toward humor), religiusitas (intelektual, ideologi, ibadah kelompok, ibadah individual, dan pengalaman religius) dan faktor demografi (jenis kelamin dan status tinggal bersama) terhadap kebahagiaan pada atau dependent variable.

Setelah melakukan uji F, maka langkah selanjutnya adalah melihat koefisien regresi dari masing - masing variabel yang diteliti terhadap kebahagiaan. Adapun kriteria yang digunakan ialah jika nilai Sig. <0.05, maka koefisien regresi tersebut signifikan. Berikut ini besaran koefisien regresi dari setiap variabel dalam penelitian dapat dilihat pada tabel 4.

Tabel 4. Koefisien Regresi

\begin{tabular}{|c|c|c|c|c|c|c|}
\hline \multirow[b]{2}{*}{ Mo } & & \multicolumn{2}{|c|}{$\begin{array}{l}\text { Unstandardized } \\
\text { Coefficients }\end{array}$} & \multirow{2}{*}{$\begin{array}{c}\text { Standardized } \\
\text { Coefficients } \\
\text { Beta }\end{array}$} & \multirow[b]{2}{*}{$\mathbf{t}$} & \multirow[b]{2}{*}{ Sig. } \\
\hline & & B & Std. Error & & & \\
\hline 1 & (Constant) & 4.336 & 5.943 & & .730 & .467 \\
\hline & Humor production & .278 & .078 & .276 & 3.570 & .000 \\
\hline & Coping with humor & -.018 & .074 & -.017 & -.241 & .809 \\
\hline & $\begin{array}{l}\text { Social uses } \\
\text { of humor }\end{array}$ & .168 & .080 & .164 & 2.092 & .038 \\
\hline & $\begin{array}{l}\text { Attitude toward } \\
\text { humor }\end{array}$ & .025 & .072 & .024 & .339 & .735 \\
\hline & Intelektual & .043 & .087 & .042 & .497 & .620 \\
\hline & Ideologi & .005 & .084 & .005 & .058 & .954 \\
\hline & Ibadah kelompok & .177 & .077 & .169 & 2.314 & .022 \\
\hline & Ibadah individual & .155 & .094 & .155 & 1.645 & .101 \\
\hline & Pengalaman & .101 & .076 & .095 & 1.335 & .183 \\
\hline & Jenis kelamin & .521 & .716 & .043 & .728 & .468 \\
\hline & Status tinggal & -.659 & .625 & -.063 & -1.055 & .293 \\
\hline
\end{tabular}

a. Dependent Variable: Kebahagiaan

Kebahagiaan $=4.336+0.276$ (humor production) -0.017 (coping with humor) +

0.164 (social uses of humor) +0.024 (attitude toward humor) +0.042 (intelektual) 0.05 (ideologi) +0.169 (ibadah kelompok) +0.155 (ibadah individual) +0.095 (pengalaman religius) +0.43 (jenis kelamin) -0.063 (status tinggal bersama). 
Berdasarkan tabel 4 di atas, signifikansi masing - masing dari independent variable dilihat dari nilai sig. Nilai sig < 0.05 menunjukkan bahwa koefisien regresi yang dihasilkan adalah signifikan. Hasil yang terdapat dalam penelitian ini menunjukkan bahwa terdapat tiga koefisien regresi yang signifikan, yaitu humor production, dan social uses of humor dan ibadah kelompok. Sedangkan delapan variabel lainnya yaitu coping with humor, attitude toward humor, intelektual, ideologi, ibadah individual, dan pengalaman religius tidak menunjukkan nilai koefisien regresi yang signifikan.

Berdasarkan hasil penelitian, ditemukan bahwa sebagian besar lansia (55.5\%) memiliki tingkat kebahagiaan yang rendah. Selanjutnya, sebesar $44.5 \%$ lansia memiliki tingkat kebahagiaan yang tinggi. Hal ini pun sejalan dengan data yang dipaparkan oleh Indeks Kebahagiaan Indonesia tahun 2017 menjelaskan bahwa semakin bertambahnya umur cenderung terjadi penurunan dalam indeks kebahagiaan penduduk di Indonesia (Berita Resmi Statistik, 2017). Hal ini pun juga dapat disebabkan oleh adanya berbagai perubahan yang terjadi dalam masa lansia, seperti kemuduran fisik dengan kulit yang mengendur, penglihatan dan pendengaran berkurang, gerakan menjadi lambat, serta interaksi sosialnya pun menjadi terbatas. Perubahan lainnya juga terjadi pada kemampuan kognitif seperti mudah lupa, kemunduran orientasi terhadap waktu dan ruang, serta tidak mudah menerima hal yang baru dapat menjadi faktor yang mempengaruhi menurunnya kebahagiaan pada lansia.

Jika dilihat berdasarkan hasil koefisien regresi dari masing - masing independent variable menujukkan bahwa terdapat pengaruh yang signifikan dari variabel sense of humor (humor production dan social uses of humor) dan variabel religiusitas (ibadah kelompok) terhadap kebahagiaan lansia di DKI Jakarta. Dalam hasil penelitian ini, aspek humor production dan social uses of humor pada variabel sense of humor serta aspek ibadah kelompok pada variabel religiusitas memiliki pengaruh dengan arah positif dan signifikan terhadap kebahagiaan lansia. Artinya, semakin tinggi tingkat humor production, social uses of humor, dan ibadah kelompok seorang lansia, maka semakin tinggi pula tingkat kebahagiaan lansia tersebut. Berdasarkan hasil tersebut, setiap variabel yang signifikan mempengaruhi kebahagiaan lansia ialah variabel yang berkaitan dengan adanya interaksi dengan orang lain, maka kebahagiaan lansia dalam penelitian ini ditentukan oleh faktor eksternal, yaitu dimana lansia dapat berinteraksi dan membangun hubungan sosial dengan orang di sekitarnya.

Bedasarkan hasil yang telah dijelaskan sebelumnya, dimensi humor production dari variabel sense of humor pada penelitian ini memiliki pengaruh yang signifikan terhadap kebahagiaan. Dengan adanya hasil tersebut, dapat disimpulkan bahwa semakin tinggi humor production yang dimiliki oleh lansia, maka semakin tinggi kebahagiaan. Humor production seringkali dikaitkan dengan kebahagiaan, hal ini dikarenakan individu memiliki kemampuan untuk menganalisa, dan menghasilkan sebuah humor yang memunculkan emosi positif bagi dirinya sendiri maupun orang lain di sekitarnya. Individu yang lebih bahagia memiliki rasa optimis, harga diri, dan terbiasa menggunakan humor secara positif dalam kesehariannya (Ford et al., 2016). Menurut Yip \& Martin (2006)individu yang memiliki sifat ceria dan gaya humor positif, berkorelasi dengan kompetensi sosial dalam lingkungannya. Selain itu Monahan (2015)menyatakan humor terbukti menjadi

http://journal.uinjkt.ac.id/index.php/tazkiya

This is an open access article under CC-BY-SA license 
intervensi yang bermanfaat dalam mengurangi stres, dapat memberikan harapan, kegembiraan, dan rasa optimis pada lansia.

Dimensi social uses of humor merupakan komponen variabel sense of humor selanjutnya yang memiliki pengaruh signifikan terhadap kebahagiaan lansia. Social uses of humor ialah kemampuan individu dalam menggunakan humor untuk berinteraksi atau bersosialisasi dengan orang lain. Berdasarkan hasil tersebut, disimpulkan bahwa semakin tinggi social uses of humor yang dimiliki lansia, maka semakin tinggi kebahagiaan. Hal ini sejalan dengan pernyataan Yip \& Martin (2006) bahwa individu yang memiliki sifat ceria dan gaya humor positif, berkorelasi dengan kompetensi sosial dalam lingkungannya. Seseorang yang lebih banyak terlibat dalam hubungan sosial yang baik, ia lebih bahagia, sehat, dan hidup lebih lama. Dengan adanya kemampuan dalam bersosialisasi, humor dapat membuat suatu kondisi yang nyaman, hangat, dan penuh rasa bahagia. Hal tersebut dapat membangun terjalinnya hubungan yang positif pada lansia terhadap lingkungannya, dan rasa aman bahwa dirinya dikelilingi oleh kerabat yang bahagia berada di dekatnya. Hal ini pun berkaitan dengan adanya pengaruh faktor tipe kepribadian yang berbeda antar individu satu dengan yang lainnya, sebagaimana menurut Johnson, A. \& David (2010) bahwa dari keempat dimesi dalam sense of humor, dimensi humor production memiliki korelasi yang signifikan dengan aspek kepribadian paling banyak dibandingkan dimensi lainnya.

Selanjutnya pada variabel religiusitas, dimensi ibadah kelompok memiliki pengaruh yang signifikan terhadap kebahagiaan. Ibadah kelompok yang dimaksud adalah individu aktif dalam berpartisipasi melakukan kegiatan keagamaan secara berkelompok atau bersama dengan orang lainnya. Hal ini pun sejalan dengan hasil studi Snoep (2008) bahwa korelasi berpartisipasi dalam kegiatan di gereja terhadap kebahagiaan lebih kuat daripada doa, meditasi, dan kepercayaan pada Tuhan. Carr (2004) menyatakan bahwa individu yang terlibat aktif dengan kegiatan keagamaan akan memberikan dampak pada hubungan sosialnya. Agama juga sering dikaitkan dengan gaya hidup sehat secara fisik maupun psikis. Hal ini juga sejalan dengan Sulandari, et.al.(2017) berdasarkan hasil penelitiannya pada lansia bahwa ikut berpartisipasi dalam kegiatan keagamaan seperti menghadiri pengajian, belajar membaca Al - Qur'an, dan kegiatan lainnya dapat memberikan manfaat yang besar dalam hidupnya, seperti rasa bahagia dan makna dalam hidup. Dengan menjalani kehidupan secara aktif, lansia akan lebih sehat dan bahagia (Santrock, 2012). Ketika mereka mengikuti kegiatan keagamaan, mereka mengisi waktu luangnya dengan mendekatkan diri pada Tuhan juga sekaligus berinteraksi dengan lingkungannya. Dengan itu lansia yang aktif mengikuti kegiatan keagamaan memperoleh ketenangan, kekuatan, serta dukungan sosial yang baik oleh orang sekitarnya, mengingat di masa senja ini mereka seringkali merasa tersisihkan oleh keluarga maupun lingkungannya.

Pada variabel sense of humor, dimensi coping with humor dan attitude toward humor tidak memiliki pengaruh yang signifikan terhadap kebahagiaan pada lansia. Hal ini pun sejalan dengan Kail \& Cavanaugh (2012) menyatakan berdasarkan berbagai penelitian, lansia di berbagai negara mengatasi permasalahan hidupnya dengan iman dan spiritualitas agama mereka, salah satunya melalui doa dan percaya kepada Tuhan. Dengan hal ini mengapa coping with humor tidak signifikan dapat disebabkan oleh lansia lebih percaya dan meyakini bahwa berbagai masalah dan 
tekanan yang dirasakannya akan berkurang dengan mendekatkan diri kepada Tuhan. Begitupun dengan attitude toward humor yang tidak mempengaruhi kebahagiaan lansia, hal ini dapat dikarenakan berbagai faktor. Menurut Jahja (2011)orang yang berada di usia lanjut kehilangan rasa dan minatnya terhadap hal yang lucu. Dengan berbagai penurunan kemampuan fisik pada lansia, hal ini pun mempengaruhi mereka dalam proses pemahaman sebuah humor. Akhirnya mereka seringkali merasa tersisihkan, maka ia lebih memfokuskan diri untuk mengisi waktunya untuk menenangkan diri dengan mendekatkan diri pada Tuhan. Hal ini pun diperkuat oleh hasil penelitian Bengtson, Silverstein, Putney, \& Harris (2015) bahwa semakin bertambahnya usia akan berkorelasi positif dengan intensitas religiusitas.

Dalam hasil penelitian ini variabel religiusitas yang tidak memiliki pengaruh signifikan terhadap kebahagiaan ialah dimensi intelektual, ideologi, ibadah individual dan pengalaman religius. Hal ini pun sejalan dengan hasil studi Snoep (2008) yang menyatakan bahwa aspek sosial lebih penting daripada pengalaman pribadi dalam agama, korelasi terkuat yang mempengaruhi kebahagiaan ialah mereka yang menghabiskan waktu bersama orang - orang di gereja menjadi prediktor kebahagiaan daripada doa, meditasi, dan kepercayaan pada Tuhan. Dengan hal ini pun, dapat menjadi alasan mengapa di penelitian ini hanya dimensi ibadah kelompok saja yang signifikan dalam mempengaruhi kebahagiaan. Berdasarkan hasil penelitian lainnya pun menyatakan bahwa tidak ada hubungan yang signifikan antara kebahagiaan dan pengaruh agama secara keseluruhan (Argyle \& Hills, 2000). Namun banyak pula yang menyatakan bahwa aspek dalam agama merupakan hal yang penting dalam mempengaruhi kebahagiaan, salah satunya ialah hasil studi Sahraian, Gholami, Javadpour, \& Omidvar (2011) menyatakan bahwa religiusitas berkorelasi positif terhadap kebahagiaan.

Berdasarkan hasil penelitian ini terdapat dua dimensi pada variabel faktor demografi yaitu jenis kelamin dan status tinggal bersama juga tidak memiliki pengaruh yang signifikan terhadap kebahagiaan lansia. Artinya, tidak ada pengaruh perbedaan gender dan status tinggal yang mempengaruhi kebahagiaan lansia. Hasil ini pun sesuai dengan studi Lobos, Grunert, Bustamante, \& Schnettler (2016) menyatakan bahwa tidak ada perbedaan yang signifikan antara kebahagiaan pada pria dan wanita. Hal ini pun dapat dikarenakan adanya jumlah yang tidak sebanding antara responden pria dan wanita. Dalam penelitian ini jumlah responden wanita $(58.3 \%)$ lebih besar dibandingkan pria (41.7\%). Maka ketidakseimbangan jumlah inilah yang dikhawatirkan mempengaruhi hasil variabel ini menjadi tidak signifikan.

Selain itu, pada dimensi status tinggal bersama tidak mempengaruhi kebahagiaan pada lansia dapat disebabkan oleh berbagai hal. Salah satunya ialah bagaimana ikatan dan hubungan lansia tersebut dengan orang yang tinggal bersamanya. Apabila jika lansia yang tinggal bersama keluarganya namun tidak memiliki komunikasi dan hubungan yang baik, dikhawatirkan akan timbul perasaan merasa dikucilkan bahkan merasa kesepian. Hal ini tentunya akan mempengaruhi kebahagiaan dan pandangan hidupnya. Jika lansia yang hanya tinggal sendiri, namun memiliki dukungan dan hubungan yang baik dengan anaknya, tentunya ia akan merasa bahagia, karena pada masa ini mereka lebih mementingkan kepuasan emosionalnya dengan menikmati waktu luang bersama orang terdekatnya. Hasil penelitian Jung \& Kim (2017) pun mengatakan bahwa 
kebahagiaan lansia lebih ditentukam oleh status perkawinan dan kesehatan daripada dengan siapa mereka tinggal. Namun penelitian lain juga ada yang menyatakan bahwa living arragements atau pengaturan kondisi hidup merupakan hal yang penting bagi kebahagiaan lansia (Chen \& Short, 2008)

Penelitian ini terdapat banyaknya keterbatasan serta kekurangan, salah satunya ialah keterbatasan dalam proses pengambilan data. Dengan adanya pandemi Covid-19 ini, memaksa peneliti untuk tidak dapat berinteraksi langsung dengan responden. Akhirnya proses pengambilan data pun secara online menggunakan google forms, metode ini memungkinkan adanya bias respon faking good dan social desirability. Bias ini dapat terjadi saat responden mengisi kuesioner yang dibantu oleh orang sekitarnya, sehingga ketika menjawab pertayaan dikhawatirkan bukanlah jawaban yang sebenarnya. Selain itu, pengambilan data ini memiliki keterbatasan ketika responden kurang memahami suatu item, peneliti tidak dapat memberikan penjelasan secara efektif dikarenakan metode online yang digunakan dan dikhawatirkan orang yang membantunya dalam mengisi keliru dalam memberikan penjelasan, sehingga akan mempengaruhi hasil dalam penelitian ini.

Selanjutnya penelitian ini juga terbatas hanya pada sampel lansia yang tinggal di rumah saja dan di wilayah DKI Jakarta. Peneliti awalnya berniat ingin mengambil sampel lansia yang juga tinggal di panti werdha, namun mengingat kondisi saat ini yang kurang memungkinkan memaksa peneliti hanya mengambil sampel yang hanya tinggal dirumah saja secara online menggunakan google forms. Penelitian ini pun terdapat jumlah sampel yang tidak merata, seperti pada jumlah setiap karakteristik responden.

Keterbatasan lainnya adalah hasil dari analisis regresi yang menunjukkan dari kesebelas variabel yang diteliti, hanya tiga variabel yang signifikan mempengaruhi dependent variable. Hal ini mengindikasikan bahwa dalam penelitian ini, peneliti kurang menelaah lebih lanjut perihal variabel lain yang menjadi prediktor kebahagiaan pada lansia. Maka dari itu dibutuhkan penelitian lebih lanjut untuk melengkapi kekurangan dan keterbatasan dalam penelitian ini.

\section{Kesimpulan}

Berdasarkan dengan hasil uji hipotesis dapat disimpulkan bahwa terdapat pengaruh yang signifikan sebesar 36.6\% dari sense of humor (humor production, coping with humor, social uses of humor, attitude toward humor), religiusitas (intelektual, ideologi, ibadah kelompok, ibadah individual, dan pengalaman religius) dan faktor demografi (jenis kelamin dan status tinggal bersama) terhadap kebahagiaan pada lansia. Kemudian, berdasarkan hasil uji hipotesis dari signifikansi masing - masing koefisien regresi terhadap kebahagiaan terdapat tiga variabel yang nilai koefisien regresinya signifikan, yaitu humor production dan social uses of humor pada variabel sense of humor, serta ibadah kelompok pada variabel religiusitas. Sementara lainnya yaitu, coping with humor, attitude toward humor, intelektual, ideologi, ibadah individual, pengalaman religius, jenis kelamin dan status tinggal bersama tidak signifikan dalam penelitian ini. 
Abde, A. N. Y., \& Salih, K. (2015). The Literature of Happiness "With reference of the Philosophy of Happiness in Islam.” Journal of Islamic Studies and Culture, 3(2). https://doi.org/10.15640/jisc.v3n2a18

Abdel-Khalek, A. M. (2006). Happiness, health, and religiosity: Significant relations. Mental Health, Religion \& Culture, 9(1), 85-97. https://doi.org/10.1080/13694670500040625

Argyle, M., \& Hills, P. (2000). Religious experiences and their relations with happiness and personality. International Journal for the Psychology of Religion, 10(3), 157-172. https://doi.org/10.1207/S15327582IJPR1003_02

Bengtson, V. L., Putney, N. M., Silverstein, M., \& Harris, S. C. (2015). Does religiousness increase with age? Age changes and generational differences over 35 years. Journal for the Scientific Study of Religion, 54(2), 363-379. https://doi.org/10.1111/jssr.12183

Berita Resmi Statistik. (2017). Indeks Kebahagiaan Indonesia Tahun 2017. Badan Pusat Statistik. https://www.bps.go.id/pressrelease/2017/08/15/1312/indeks-kebahagiaan-indonesia-tahun2017-sebesar-70-69-pada-skala-0-100.html

Carr, A. (2004). Carr, A. (2004). Positive psychology: New worlds for old. Irish Psychologist, 30 (11), 278-279.

https://www.academia.edu/11423794/Carr_A_2004_Positive_psychology_New_worlds_for _old_Irish_Psychologist_30_11_278_279

Chen, F., \& Short, S. E. (2008). Household Context and Subjective Well-Being Among the Oldest Old in China. Journal of Family Issues, 29(10), 1379-1403. https://doi.org/10.1177/0192513X07313602 
Ekasari, M. F., Riasmini, N. M., \& Hartini, T. (2019). MENINGKATKAN KUALITAS HIDUP LANSIA KONSEP DAN BERBAGAI INTERVENSI. WINEKA MEDIA.

Ford, T. E., Lappi, S. K., \& Holden, C. J. (2016). Personality, Humor Styles and Happiness: Happy People Have Positive Humor Styles. Europe's Journal of Psychology, 12(3), 320-337. https://doi.org/10.5964/ejop.v12i3.1160

Haybron, D. M. (2005). On Being Happy or Unhappy1. Philosophy and Phenomenological Research, 71(2), 287-317. https://doi.org/10.1111/j.1933-1592.2005.tb00450.x

Hoyer, W. J., \& Roodin, P. (2003). Adult Development and Aging. McGraw-Hill.

Huber, S., \& Huber, O. W. (2012). The Centrality of Religiosity Scale (CRS). Religions, 3(3), 710724. https://doi.org/10.3390/rel3030710

Jahja, Y. (2011). Psikologi Perkembangan. Kencana.

Johnson, A., \& McCord, D. M. (2010). Relating Sense of humor to the Five Factor Theory Personality Domains and Facets. 9.

Jung, J., \& Kim, I. (2017). Effects of living arrangements of the urban elderly on their subjective wellbeing: A comparison between Korea and China. Cogent Social Sciences, 3(1), 1268288. https://doi.org/10.1080/23311886.2016.1268288

Kail, R. V., \& Cavanaugh, J. C. (2012). Cengage Advantage Books: Human Development: A LifeSpan View (6th edition). Wadsworth Publishing.

Kaliterna-Lipovčan, L., \& Prizmić-Larsen, Z. (2016). What differs between happy and unhappy people? SpringerPlus, 5(1), 225. https://doi.org/10.1186/s40064-016-1929-7 
Kalmijn, W. M., Arends, L. R., \& Veenhoven, R. (2011). Happiness Scale Interval Study. Methodological Considerations. Social Indicators Research, 102(3), 497-515. https://doi.org/10.1007/s11205-010-9688-2

Kehn, D. J. (1995). Predictors of elderly happiness. Activities, Adaptation \& Aging, 19(3), 11-30. https://doi.org/10.1300/J016v19n03_02

Latipun, Nisa, W. I., \& Winarsunu, T. (2019). The Sense of humor as Mediator Variable of the Relationship Self-Esteem and Happiness Among the Elderly in the Villages of Indonesia. Research on Humanities and Social Sciences, 9(6), 30-35.

Lobos, G., Grunert, K. G., Bustamante, M., \& Schnettler, B. (2016). With Health and Good Food, Great Life! Gender Differences and Happiness in Chilean Rural Older Adults. Social Indicators Research, 127(2), 865-885. https://doi.org/10.1007/s11205-015-0971-0

Lyubomirsky, S., \& Kurtz, J. (2013). Positively Happy: Routes to Sustainable Happiness. CreateSpace Independent Publishing Platform.

Monahan, K. (2015). The Use of Humor With Older Adults Aging in Place. Social Work in Mental Health, 13, 61-69. https://doi.org/10.1080/15332985.2014.918922

Puspita, A. (2015). THE RELATIONSHIP BETWEEN SENSE OF HUMOR AND HAPPINESS IN ELDERLY. 7.

Rokom. (2019). Indonesia Masuki Periode Aging Population—Sehat Negeriku. http://sehatnegeriku.kemkes.go.id/baca/rilis-media/20190704/4530734/indonesia-masukiperiode-aging-population/ 
Sahraian, A., Gholami, A., Javadpour, A., \& Omidvar, B. (2011). Association Between Religiosity and Happiness Among a Group of Muslim Undergraduate Students. Journal of Religion and Health. https://doi.org/10.1007/s10943-011-9484-6

Santrock, J. W. (2012). Life-span development: Perkembangan masa hidup (jilid 2). Penerbit Erlangga.

Seligman, M. E. P. (2002). Authentic happiness: Using the new positive psychology to realize your potential for lasting fulfillment. Free Press.

http://ebook.3m.com/library/neworleanspubliclibrary-document_id-anc7hr9

Snoep, L. (2008). Religiousness and happiness in three nations: A research note. Journal of Happiness Studies, 9(2), 207-211. https://doi.org/10.1007/s10902-007-9045-6

Snyder, C. R., Lopez, S. J., \& Pedrotti, J. T. (2015). Positive psychology: The scientific and practical explorations of human strengths.

Sulandari, S., Wijayanti, M., \& Pornamasari, R. D. (2017). Keterlibatan Lansia dalam Pengajian: Manfaat Spiritual, Sosial, dan Psikologis. Indigenous: Jurnal Ilmiah Psikologi, 1(2), Article 2. https://doi.org/10.23917/indigenous.v1i2.2906

Thorson, J. A., \& Powell, F. C. (1993). Development and validation of a Multidimensional Sense of humor Scale. Journal of Clinical Psychology, 49(1), 13-23. https://doi.org/10.1002/10974679(199301)49:1<13::AID-JCLP2270490103>3.0.CO;2-S

Tse, M. M. Y., Lo, A. P. K., Cheng, T. L. Y., Chan, E. K. K., Chan, A. H. Y., \& Chung, H. S. W. (2010, June 28). Humor Therapy: Relieving Chronic Pain and Enhancing Happiness for Older Adults [Research Article]. Journal of Aging Research; Hindawi. https://doi.org/10.4061/2010/343574 
TAZKIYA (Journal of Psychology), 8(2), 2020

Yip, J. A., \& Martin, R. A. (2006). Sense of humor, emotional intelligence, and social competence. Journal of Research in Personality, 40(6), 1202-1208.

https://doi.org/10.1016/j.jrp.2005.08.005 